\title{
Presentation of Original Research at the European \\ Congress of Radiology 2010: Frequency of Publication \\ in Medline-Indexed Journals Within 5 Years After \\ Presentation
}

\author{
Präsentation wissenschaftlicher Originalarbeiten \\ auf dem Europäischen Röntgenkongress 2010: \\ Veröffentlichungshäufigkeit in Medline-indexed \\ Zeitschriften innerhalb von 5 Jahren nach Präsentation
}

\begin{abstract}
Authors
Marco Dollinger ${ }^{1}$, Florian Zeman ${ }^{2}$, René Müller-Wille ${ }^{3}$, Lukas Philipp Beyer ${ }^{1}$, Christian Stroszczynski ${ }^{1}$, Thorsten Alexander Bley ${ }^{4}$, Philipp Wiggermann ${ }^{1}$
\end{abstract}

Affiliations

1 Department of Radiology, University Medical Center Regensburg, Germany

2 Center for Clinical Studies, University Medical Center Regensburg, Germany

3 Department of Radiology, University Medical Center Göttingen, Germany

4 Diagnostic and Interventional Radiology, University of Würzburg, Germany

Key words

health policy and practice, statistics, radiology research

received 18.04 .2017

accepted 07.11 .2017

Bibliography

DOI https://doi.org/10.1055/s-0043-123473

Published online: 7.3.2018

Fortschr Röntgenstr 2017; 189: 327-333

(c) Georg Thieme Verlag KG, Stuttgart · New York

ISSN 1438-9029

Correspondence

Marco Dollinger

Department of Radiology, University Medical Center

Regensburg, Franz-Josef-Strauß-Allee 11,

93053 Regensburg, Germany

Tel.: ++ 49/944/74 10

marco.dollinger@ukr.de

\section{ZUSAMMENFASSUNG}

Hintergrund Bestimmung der Häufigkeit, mit welcher mündlich vorgetragene wissenschaftliche Originalarbeiten des Europäischen Röntgenkongresses (ECR) 2010 in Medlinegelisteten Zeitschriften veröffentlicht wurden sowie Erhebung entsprechender prädiktiver Faktoren.
Methode Insgesamt wurden 869 Abstracts in die Studie eingeschlossen. Alle im Programmheft des ECR 2010 aufgeführten wissenschaftlichen Abstracts wurden auf eine mögliche nachfolgende Veröffentlichung im Zeitraum März 2010 bis Februar 2015 hin ausgewertet. Hierzu erfolgte eine Medlinebasierte Suche unter Zuhilfenahme der Erst-, Zweit- und/oder Letztautoren der jeweiligen Abstracts im ECR-Programmeft. Das Veröffentlichungsjahr, die Zeitschrift, das Ursprungsland, das Teilgebiet und die Art der wissenschaftlichen Arbeit (d. h. Patienten-/Probandenstudie, tierexperimentelle Studie oder methodisch-technische Studie) wurden aufgezeichnet.

Ergebnisse Im Zeitraum März 2010 bis Februar 2015 wurden insgesamt 450 Abstracts (Veröffentlichungsrate, 51,8\%) in 125 Medline gelisteten Zeitschriften veröffentlicht, vornehmlich im European Radiology (11,1\%). In 443/450 (98,4\%) Fällen wurde die Arbeit auf Englisch veröffentlicht. Studien aus den Teilgebieten molekularer bzw. kardialer Bildgebung hatten die höchsten (75,0\% bzw. 62,0\%), Studien aus dem Gebiet der Computeranwendungen die niedrigsten (27,6\%) Veröffentlichungsraten. Die Art der wissenschaftlichen Arbeit, das Ursprungland des Abstracts sowie das Teilgebiet beeinflussten die Veröffentlichungsrate signifikant.

Schlussfolgerung Über die Hälfte der mündlich auf dem ECR 2010 präsentierten wissenschaftlichen Originalarbeiten wurden nachfolgend in Medline-gelisteten Zeitschriften veröffentlicht. Es wurden mehr Artikel in der Zeitschrift European Radiology veröffentlicht als in einem anderen identifiziertem Journal.

\section{Kernaussagen:}

- Der ECR 2010 hatte eine hohe nachfolgende Veröffentlichungsrate

- Die meisten nachfolgend veröffentlichten Artikel wurden in radiologischen Fachzeitschriften veröffentlicht

- Nahezu alle Artikel wurden in englischer Sprache veröffentlicht 
ABSTRACT

Objectives To determine the rate at which original studies presented orally at the European Congress of Radiology (ECR) 2010 were published in Medline-indexed journals and to identify factors predictive of publication.

Methods A total of 869 abstracts were included in the study. A Medline search of articles published between March 2010 and February 2015 was conducted to identify articles written by the first, second, and/or last authors of all abstracts published in the Scientific Program of ECR 2010. The publication year, journal, country of origin, subspecialty and nature of the research (i. e., human, animal or technical) were recorded.

Results Between March 2010 and February 2015 a total of 450 abstracts (publication rate, $51.8 \%$ ) were subsequently published in 125 Medline-indexed journals, chiefly in European Radiology (11.1\%). 443/450 (98.4\%) articles were published in English language. The subspecialties of molecular imaging and cardiac imaging had the highest publication rates $(75.0 \%$ and $62.0 \%$, respectively), while computer appli- cation studies had the lowest (27.6\%). The nature of research, origin of the abstract and subspecialty significantly influenced the subsequent publication rate.

Conclusion More than half of the original studies presented orally at ECR 2010 were subsequently published in Medline-indexed journals. More articles were published in the journal European Radiology than in any other identified journal.

Key Points:

- ECR 2010 had a high subsequent publication rate

- Most subsequently published articles were published in radiology journals

- Nearly all articles were published in the English language

\section{Citation Format}

- Dollinger M, Zeman F, Müller-Wille R et al. Presentation of Original Research at the European Congress of Radiology 2010: Frequency of Publication in Medline-Indexed Journals Within 5 Years After Presentation. Fortschr Röntgenstr 2017; 189: 327-333

\section{Introduction}

National and international scientific conferences are important platforms where original research data are presented and discussed. These meetings have the advantages of rapid communication, immediate exchange of experiences and the opportunity to interact directly with other researchers. The next step in bringing research data to the scientific community involves written publication in a scientific journal. In the field of radiology, publication rates range from $11 \%$ to $47 \%$ [ 1 - 5]. Sometimes high publication rates are an indicator of the scientific level of a congress [2]. However, previously published studies have shown that publication rates depend on different factors, which are partly independent of the quality of research [6].

In Europe, the most relevant European congress to present original research data in the field of radiology is the European Congress of Radiology (ECR), which is held annually in Vienna. In 2010, this congress included more than 19000 delegates from 96 countries, with nearly 12000 professional medical delegates among them [7]. A preliminary study published by Loughborough et al. evaluated selected data from scientific presentations at ECR 2010 in a follow-up of 4 years, 9 months [8].

Since the results of several studies have shown that the majority of articles are published within five years after the material is presented at a conference [ $9-12]$, the aim of this study was to determine the subsequent publication rate in Medline-indexed journals from presentations at ECR 2010 in a follow-up of 5 years. Moreover, the study evaluated the publication year, language of publication, relationship to country of origin of abstracts, radiologic subspecialty, journal, concordance of the order of the first author and the study sample size in the abstract compared to those of the derived article.

\section{Materials and Methods}

\section{Original research studies}

One reader identified all ECR 2010 orally presented original studies by studying the final program abstract book [13]. The 869 identified abstracts were classified according to the following:

a) the radiologic subspecialty as indicated in the program book;

b) the country from which the abstract was submitted, as indicated in the program book (additionally classified as Europe, USA or other countries). The definition of Europe included the 27 countries of the European Union as of 2010 plus BosniaHerzegovina, Belarus, Croatia, Macedonia, Moldavia, Norway, Switzerland, Turkey and the Ukraine;

c) the study subjects and materials involved patients and/or healthy volunteers, animals or methodological and technical materials. Abstract subjects and material were classified as patients and/or healthy volunteers if the abstract contained both human and animal or methodological and technical data, as animals if it contained both animal and methodological and technical data but no human data and as methodological and technical materials if it contained neither human nor animal data.

\section{Study search and data collection}

The subsequent publication rate for the corresponding studies was identified by scanning Medline on the PubMed server (www.ncbi.nlm.nih.gov/PubMed/) for the five-year period following the ECR 2010 Scientific Assembly, defined as March 2010 to February 2015. The first year after ECR 2010 was defined as the time interval between March 2010 and February 2011. The second year after ECR 2010 was defined as the period between March 2011 and February 2012, and so on. Abstracts that were withdrawn were excluded from the study. 
A Medline search was performed by using the first initial(s) and the full family name of the leading author. If this search failed, the same procedure was conducted for the second author and - if it failed again - for the last author. If the search revealed more than 20 references, an appropriate keyword from the title of the abstract was added before the search was repeated.

Only original articles corresponding to the abstract were selected; letters, reviews and editorials were excluded. Moreover, articles published before March 2010, those with related abstracts presented at the congress and articles in which the number of described study subjects, animals or experiments was more than three times that cited in the abstract were excluded. These criteria were established because such abstracts likely corresponded to very preliminary work that was followed up in a major study bearing little resemblance to the initial protocol.

The concordance between the information contained in the summary of the published article and that cited in the abstract of the oral presentation was verified.

The following variables were assessed:

a) the year of publication;

b) the language of the published article;

c) the journal of the published article (classified as radiology and non-radiology journals; radiology journals were considered to be all those included in the subject listing "diagnostic imaging", "radiology", "magnetic resonance" and "computed tomography");

d) the position of the first author in the abstract in comparison to the position in the published article;

e) the size of the study sample, considered as the number of patients, volunteers, animals or methodological and technical materials (classified as lower, similar or higher than those of the oral presentation);

f) publication rates from countries with ten or more derived articles published from the abstract presentations;

g) the radiologic subspecialty.

Data are presented as absolute numbers and relative frequencies. Publication rates between different factors were compared using Pearson's chi-squared test. A p-value $<0.05$ was considered statistically significant. All analyses were performed using SPSS 24.0 (SPSS Inc., Chicago, IL, USA).

\section{Results}

\section{Subspecialties, countries, and subjects}

The 869 abstracts focused on the following 18 radiologic subspecialties, in decreasing order of frequency: interventional radiology (90/869, 10.4\%), neuro (80/869, 9.2\%), abdominal viscera (solid organs) (79/869, 9.1\%), musculoskeletal (79/869, 9.1\%), cardiac (79/869, 9.1\%), chest $(60 / 869,6.9 \%)$, breast $(59 / 869,6.8 \%)$, gastrointestinal tract $(58 / 869,6.7 \%)$, vascular (50/869, 5.8\%), genitourinary (49/869, 5.6\%), abdomen (40/869, 4.6\%), physics in radiology (39/869, $4.5 \%$ ), pediatric (30/869, $3.5 \%)$, computer applications (29/869, $3.3 \%$ ), head and neck (29/869, $3.3 \%$ ), molecular imaging (20/869, $2.3 \%)$, radiographers (20/869, $2.3 \%$ ) and contrast media (19/869, 2.2\%) (• Fig. 1).

The abstracts originated from a total of 41 countries, as indicated in the program book: $78.0 \%$ from European countries (678/ 869), $4.0 \%$ from the United States (35/869) and $18.0 \%$ from other countries (156/869). 10 or more abstracts originated from each of the following 15 countries: Germany (236/869, 27.2\%), Italy (138/ 869, $15.9 \%)$, China (54/869, 6.2\%), The Netherlands (49/869, $5.6 \%)$, Korea (42/869, $4.8 \%)$, Switzerland (41/869, $4.7 \%)$, France (39/869, $4.5 \%)$, United Kingdom (37/869, $4.3 \%)$, Austria (37/869, $4.3 \%$ ), United States (35/869, 4.0\%), Japan (20/869, $2.3 \%$ ), Greece (16/869, $1.8 \%)$, Spain (16/869, $1.8 \%)$, Poland (10/869, $1.2 \%$ ) and India (10/869, $1.2 \%$ ) ( Table 1$)$. The other $89 / 869$ abstracts (10.2\%) originated from the remaining 26 countries.

The abstracts referred to studies involving patients and/or healthy volunteers in $742 / 869(85.4 \%)$ cases, studies involving animals in $45 / 869(5.2 \%)$ cases and studies involving purely methodological and technical work in 82/869 (9.4\%) cases.

\section{Journals, languages and years in which articles were published}

Between March 2010 and February 2015, 450 of the 869 abstracts presented at ECR 2010 were expanded into articles that were published in Medline-indexed journals, resulting in a publication rate of $51.8 \%$. Concerning the year of publication, 134/450 (29.8\%), 168/450 (37.3\%), 91/450 (20.2\%), 38/450 (8.4\%) and 19/450 (4.2\%) articles were published within the first, second, third, fourth and fifth year after ECR 2010, respectively. Thus, $87.3 \%$ (393/450) of these articles were published during the first three years after the 2010 scientific assembly.

The articles were published in a total of 125 journals, including, in decreasing order of frequency, European Radiology (50/450, $11.1 \%)$, European Journal of Radiology (48/450, 10.7\%), Investigative Radiology (35/450, 7.8\%), Radiology (29/450, 6.4\%), American Journal of Roentgenology (21/450, 4.7\%), Academic Radiology (17/450, 3.8\%), American Journal of Neuroradiology (15/450, 3.3\%), Journal of Magnetic Resonance Imaging (12/450, $2.7 \%)$, British Journal of Radiology (11/450, $2.4 \%)$, RöFo - Fortschritte auf dem Gebiet der Röntgenstrahlen und der bildgebenden Verfahren $(11 / 450,2.4 \%)$ and La Radiologica Medica (10/450, $2.2 \%)$. The other $191 / 450$ (42.4\%) articles were published in 114 journals (fewer than 10 articles published in each). Thus, more than half $(259 / 450,55.3 \%)$ of the articles were published in only 11 journals ( 10 or more articles published in each). $317 / 450(70.4 \%)$ articles were published in radiology journals. 443/450 (98.4\%) articles were published in English, $4 / 450$ (0.9\%) in German, 2/450 (0.4\%) in Chinese and 1/450 $(0.2 \%)$ in Spanish.

The size of the study sample was similar to that of the abstracts in $45.8 \%(206 / 450)$ of the articles, higher in $32.4 \%(146 / 450)$ and lower in $15.6 \%(70 / 450)$. In $6.2 \%$ (28/450), it was not possible to compare the study sample of the published paper and oral presentation because it was a phantom study or the exact sample size was not mentioned in one or both of the abstracts. Therefore, $48.0 \%(216 / 450)$ of papers had a different sample size than in the presentations at ECR 2010. 


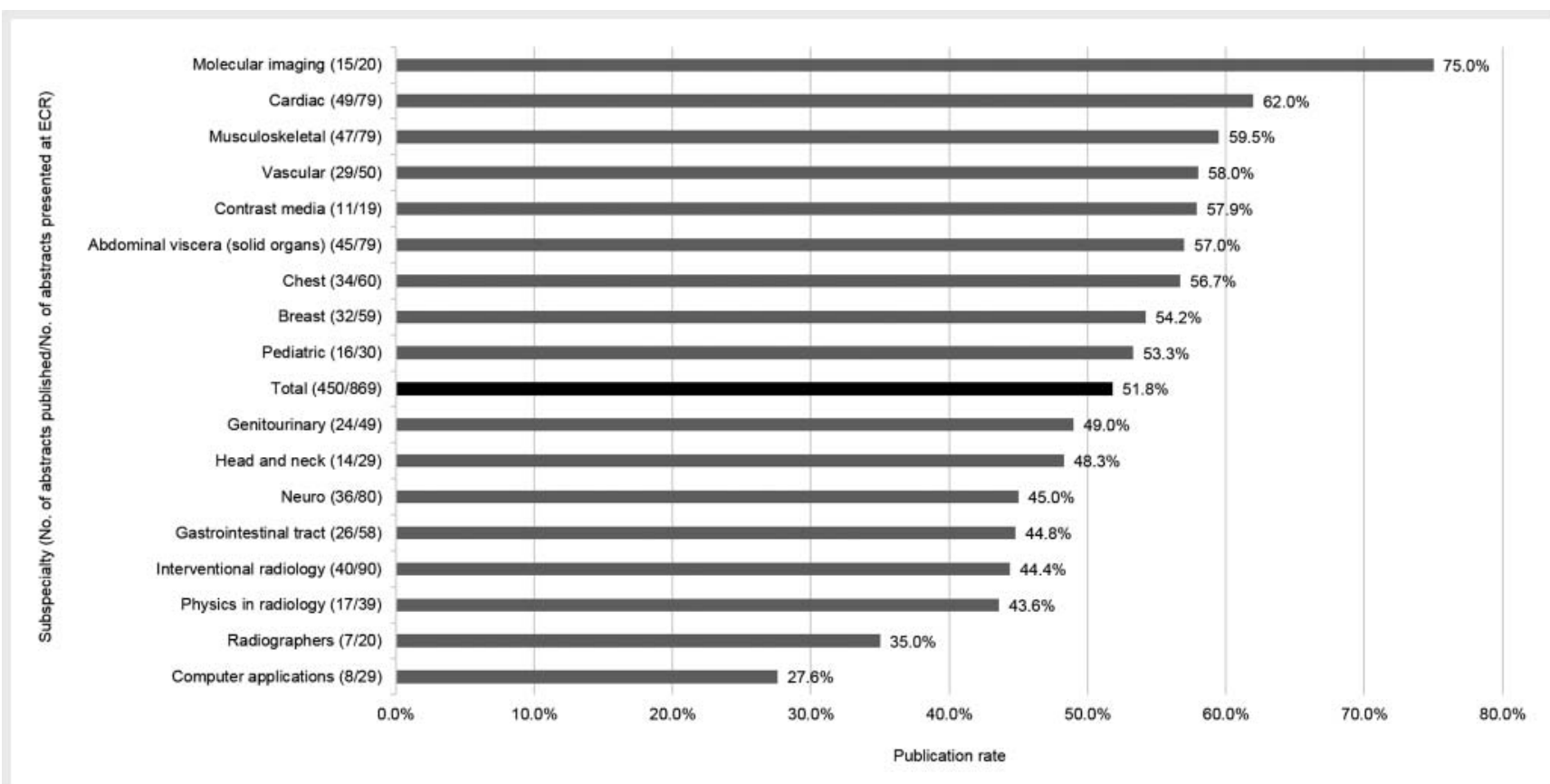

- Fig. 1 Publication rates of orally presented original studies at European Congress of Radiology 2010 according to radiologic subspecialty as indicated in the program book. No., number. ECR, European Congress of Radiology.

- Abb. 1 Veröffentlichungsrate mündlich vorgetragener wissenschaftlicher Originalarbeiten auf dem Europäischen Röntgenkongress 2010 bezogen auf die im Programmheft angegebene radiologische Subspezialität. No., Anzahl. ECR, Europäischer Röntgenkongress.

The first author in the abstract was listed as the first, second, third, fourth or later, or the last author or did not appear at all at the published article in $75.8 \%$ (341/450), $8.4 \%$ (38/450), $2.7 \%$ (12/450), $3.3 \%$ (15/450), $6.0 \%$ (27/450) and $3.8 \%(17 / 450)$ of cases, respectively.

\section{Factors predictive of publication}

Molecular imaging studies and cardiac imaging studies showed the highest publication rates: $75.0 \%$ (15/20) and 62.0\% (49/79), respectively. Computer applications exhibited the lowest publication rate of $27.6 \%(8 / 29)$ ( $\triangleright$ Fig. 1 ). The subspecialty of the abstract significantly influenced the likelihood of subsequent publication $(p=0.040)$.

The publication rate depended on the country from which the abstract originated. Comparing the publication rate of the 10 countries with the most abstracts (more than 30 abstracts each from Germany, Italy, China, The Netherlands, Korea, Switzerland, France, United Kingdom, Austria, and United States), articles from these countries were more likely to be published than if they originated from the other 31 countries (390/708 (55.1\%) vs. 60/161 $(37.3 \%)$, respectively, $p<0.001)$. Furthermore, there was a significant difference $(p<0.001)$ in the publication rate among the top 10 countries ( $\vee$ Table $\mathbf{1}$ ).

Regarding the study subjects and materials involved, animal studies showed the highest publication rate at $57.8 \%$ (26/45), followed by studies including patients and/or healthy volunteers (53.0\%, 393/742). Methodological and technical studies showed the lowest publication rate at $37.8 \%(31 / 82), p=0.024$.

\section{Discussion}

Of the 869 original studies presented orally at ECR 2010, 450 - or more than one-half - were subsequently published in Medline-indexed journals. The majority of the articles were published in English-language journals. Most of them were published in one journal, European Radiology. A total of $87.3 \%$ (393/450) of the articles were published within the first three years after ECR 2010.

Because the aim of the present study was to evaluate the rate of subsequent publication of orally presented abstracts, articles that were published before March 2010 were not considered. Because this study covered the five years after ECR 2010, i. e., March 2010 through February 2014, it is possible that single articles that were published after this date were missed. However, according to previously published studies, the mean time to publication after oral presentation at medical conferences is between 1 and 1.5 years [3, 9, 10]. Arrivé et al. [2] and Miguel-Dasit et al. [5] reported that $94 \%$ and $80 \%$ of articles were published within three years after the 1995 RSNA Scientific Assembly and ECR 2000 , respectively. The results of the current study are in line with these reports: $87.3 \%$ of articles were published within three years after ECR 2010.

Published articles originating from ECR 2010 presentations were identified by searching for the authors' last names, a technique that has been described in several similar studies [2, 5]. However, the efficiency of this technique does not seem to have been evaluated until now. This search method entails the risk of missing a published article for reasons including major changes 
- Table 1 Publication rates according to country of origin, including countries that had at least ten oral presentations at European Congress of Radiology 2010. No., number.

- Tab. 1 Veröffentlichungsrate in Bezug auf das Ursprungsland unter Berücksichtigung von Ländern, die mindestens 10 mündliche Präsentationen auf dem Europäischen Röntgenkongress 2010 hatten. No., Anzahl.

\begin{tabular}{|l|c|l|l|}
\hline $\begin{array}{l}\text { country } \\
\text { of origin }\end{array}$ & $\begin{array}{l}\text { no. of } \\
\text { abstracts }\end{array}$ & $\begin{array}{l}\text { no. of } \\
\text { abstracts } \\
\text { published }\end{array}$ & $\begin{array}{l}\text { publication } \\
\text { rate }\end{array}$ \\
\hline Austria & 37 & 18 & $48.6 \%$ \\
\hline China & 54 & 17 & $31.5 \%$ \\
\hline France & 39 & 26 & $66.7 \%$ \\
\hline Germany & 236 & 138 & $58.5 \%$ \\
\hline Greece & 16 & 8 & $50.0 \%$ \\
\hline India & 10 & 0 & $0.0 \%$ \\
\hline Italy & 138 & 63 & $45.7 \%$ \\
\hline Japan & 20 & 12 & $60.0 \%$ \\
\hline Korea & 42 & 27 & $64.3 \%$ \\
\hline The Netherlands & 49 & 36 & $73.5 \%$ \\
\hline Poland & 10 & 5 & $50.0 \%$ \\
\hline Spain & 16 & 1 & $6.3 \%$ \\
\hline Switzerland & 41 & 29 & $70.7 \%$ \\
\hline United King- & 37 & 19 & $51.4 \%$ \\
\hline dom & 35 & 17 & $48.6 \%$ \\
\hline United States & 35 & & \\
\hline & & & \\
\hline
\end{tabular}

of the first author's name, misspelling of the first author's last name or that the name of the first author of the abstract was removed on the subsequent publication. According to Miguel-Dasit and colleagues [5], the first author of the oral presentation at ECR 2000 was not included as an author on the resulting full article in $7 \%$ of cases and there was changed author position in $24 \%$ of cases. This finding is consistent with the results of the current study, in which the first author of the abstract presented at ECR 2010 was absent or in a changed position in the subsequent full article in $3.8 \%(17 / 450)$ and $20.4 \%(92 / 450)$ of publications, respectively. To avoid or at least minimize the risks mentioned above of missing a published article, unsuccessful searches with the first author's name were repeated by using the last name of the second author and, if necessary, the last name of the last author. Consequently, the publication rate of $51.8 \%$ of abstracts presented at ECR 2010 might be slightly lower than the actual publication rate. Alternatively, the subsequent publication rate could have been evaluated by a questionnaire-based survey of the authors in question. However, because ECR is the second-largest radiological meeting worldwide, this approach would have been extremely difficult.

Of the abstracts presented at ECR 2010, 78.0\% (678/869) originated from Europe, 4.0 \% (35/869) from the United States and $18.0 \%(156 / 869)$ from other countries. Out of the European abstracts, Germany and Italy contributed the most, with approximately one-third $(34.8 \%, 236 / 678)$ and one-fifth $(20.3 \%$, $138 / 678)$, respectively. These percentages are similar to those reported from ECR 2000 , with $80.3 \%$ of the abstracts originating from Europe, $2.1 \%$ from the United States, and $17.5 \%$ from other countries. At ECR 2000, the prevalence of Italian abstracts among the European abstracts ( $80.3 \%$ of all abstracts) was $19.2 \%$, similar to the current results with $20.4 \%$ (138/678). However, the proportion of German abstracts among European abstracts was slightly higher in 2000 , with $41.8 \%$ [5] compared to $34.8 \%$ $(236 / 678)$ in the current study.

The $51.8 \%$ publication rate for articles from studies presented orally at ECR 2010 is similar to the publication rate reported after ECR 2000, with $47.0 \%$ [5]. However, this rate is higher than that for the field of radiology in previously published articles ranging from $9-37 \%$ [2-4, 14]. Regarding other medical disciplines, publication rates of abstracts orally presented at the respective meetings range from $44 \%$ for abstracts presented at the meetings of four anesthesia societies [15] to $74 \%$ for large randomized trials presented at annual meetings of the American Society of Clinical Oncology [16].

Whereas $83.9 \%$ of the fully published articles related to oral presentations at ECR 2000 were published in English [5], this number rose to $98.6 \%$ in the current study, highlighting the predominance of the English language in current medical research [17]. This finding is also emphasized by the fact that in the current study only 4/156 (2.6\%) fully published articles that were presented at ECR 2010 and originated from German-speaking countries (Austria and Germany) were published in the German language. The remaining 152/156 articles (97.4\%) were published in English. At ECR 2000, $27 \%$ of the fully published articles that were presented at the scientific meeting and originated from Germanspeaking countries were published in German compared to $73 \%$ in English [5].

It is possible that the radiologic subspecialty of the oral presentation might influence the publication rate. In the current study, the subspecialty of molecular imaging showed a rate of $75.0 \%$ (15/20), the highest publication rate, followed by cardiac imaging studies, with $62.0 \%$ (49/79). Meanwhile, computer applications showed the lowest publication rate, with $27.6 \%$ (8/29). Considering that molecular imaging was not represented at ECR 2000, this ranking is similar to ECR 2000, with cardiac imaging studies having the highest and computer applications the lowest publication rates [5]. Finally, oral presentations of methodological and technical studies were expanded and published significantly less frequently than were oral presentations of patients and/or healthy volunteers or animal studies.

Among the 450 abstracts from ECR 2010 that were expanded into manuscripts, most articles were published in radiology journals (70.4\%), with European Radiology being the journal that published more articles than any other journal (11.1\%, 50/450). Similar proportions were found after ECR 2000, in that most articles were published in radiology journals (76.8\%) and European Radiology published more articles than any other journal [5].

Although subsequent publication of a study presented at a congress should be the aim of scientific work, nearly half of the abstracts (419/869, 48.2\%) presented at ECR 2010 were not pub- 
lished as manuscripts. Previous published studies have evaluated the reasons for an abstract not being published. These included lack of time for writing the article, authors considering their results not important enough or doubting the acceptance of the manuscript, a negative study result, an ongoing study, difficulties with co-authors and low priority for submitting a manuscript [18, 19]. Obviously, publishing a manuscript in a scientific journal does not seem to be the goal of all medical researchers who present their results at scientific conferences. The authors of the current study presume that rejection of a manuscript might also play an important role in not publishing one's scientific work although, according to Weber et al. [18], rejection of a manuscript by a journal seems to be a minor factor related to not publishing in scientific journals. Among the oral presentations at scientific congresses that were not published, $80 \%$ were not submitted to a journal; only $20 \%$ of unpublished presentations were submitted to a journal [18].

There were several limitations to the present study. First, our method of identifying published articles may have led us to miss some published manuscripts. Our literature search was also restricted to journals indexed in Medline. Accordingly, it is possible that articles that were published in journals not indexed in Medline were missed. Moreover, only fully published papers within the first five years after ECR 2010 were considered, as the aim of the study was to evaluate the rate of subsequent publication of orally presented scientific work at ECR 2010. It is probable that single articles were missed because they were published before ECR 2010 or after the five-year interval we observed. Moreover, search errors cannot be excluded, e. g., misspelling the names of the authors. Major changes to author names present another risk of overlooking singular manuscripts. However, this risk was minimized by cross-searching the investigators. Finally, an abstract was considered published if the abstract and the proposed published manuscript had similar hypotheses and designs. If the information from the abstract was ultimately buried in another article, this abstract would not have been counted as published.

\section{Conclusion}

More than half of the original studies initially presented orally as abstracts at ECR 2010 were subsequently published in Medline-indexed journals. Articles were published within three years after the meeting in $87.3 \%$ of cases. More articles were published in European Radiology than in any other identified journal. The subspecialty of the abstract significantly influenced the likelihood of subsequent publication with molecular imaging and cardiac imaging studies showing the highest publication rates, and computer applications showing the lowest publication rates. Animal studies and studies including patients and/or healthy volunteers were more likely to be published than methodological and technical studies. Abstracts originating from the 10 countries with the most abstracts presented at ECR 2010 were more likely to be published than if they originated from the other 31 countries.

Despite the results presented in this study, the authors want to emphasize that, for the sake of scientific progress, scientists, potential authors, editors and organizers of scientific meetings should not draw definite conclusions from the presented results. Altering scientific focus just for the purpose of enhanced publication probability might forego very important scientific findings. The low publication rates for certain areas can either be caused by the only marginal scientific impact of presented abstracts or by a lack of suitable journals.

\section{CLINICAL RELEVANCE OF THE STUDY}

- Rapid manuscript publication of congress abstracts indicates a good transfer of scientific knowledge from congresses to formal scientific publications in the field of radiology.

- This allows clinicians to get state-of-the-art scientific knowledge with clinical relevance not only at congresses but also in established scientific journals.

- The high propensity to publish scientific manuscripts in radiology journals indicates that radiologic journals cover most relevant research in this field.

\section{Conflict of Interest}

The authors declare that they have no conflict of interest.

\section{References}

[1] Secil M, Ucar G, Senturk C et al. Publication rates of scientific presentations in Turkish national radiology congresses. Diagnostic and Interventional Radiology 2005; 11: 69-73

[2] Arrive L, Boelle P, Dono P et al. Subsequent publication of orally presented original studies within 5 years after 1995 RSNA Scientific Assembly. Radiology 2004; 232: 101-106

[3] Bydder SA, Joseph DJ, Spry NA. Publication rates of abstracts presented at annual scientific meetings: how does the Royal Australian and New Zealand College of Radiologists compare? Australas Radiol 2004; 48: $25-28$

[4] Marx WF, Cloft H], Do HM et al. The fate of neuroradiologic abstracts presented at national meetings in 1993: rate of subsequent publication in peer-reviewed, indexed journals. American Journal of Neuroradiology 1999; 20: $1173-1177$

[5] Miguel-Dasit A, Marti-Bonmati L, Sanfeliu P et al. Scientific papers presented at the European Congress of Radiology 2000: publication rates and characteristics during the period 2000-2004. European Radiology 2006; 16: $445-450$

[6] Dickersin K, Min YI, Meinert CL. Factors influencing publication of research results. Follow-up of applications submitted to two institutional review boards. The Journal of the American Medical Association 1992; 267: $374-378$

[7] European Society of Radiology. 2010. [1 November 2016]. Available from: http://www.myesr.org/html/img/pool/ECR_2010_Participationfigures.pdf

[8] Loughborough W, Dale H, Wareham JH et al. Characteristics and trends in publication of scientific papers presented at the European Congress of Radiology: a comparison between 2000 and 2010. Insights Imaging 2016; 7: 755-762

[9] Juzych MS, Shin DH, Coffey JB et al. Pattern of publication of ophthalmic abstracts in peer-reviewed journals. Ophthalmology 1991; 98: 553-556 
[10] Nguyen V, Tornetta P, Bkaric M. Publication rates for the scientific sessions of the OTA. Orthopaedic Trauma Association. Journal of Orthopaedic Trauma 1998; 12: 457-459; discussion 456

[11] Callaham ML, Wears RL, Weber EJ et al. Positive-outcome bias and other limitations in the outcome of research abstracts submitted to a scientific meeting. JAMA 1998; 280: 254-257

[12] de Bellefeuille C, Morrison CA, Tannock IF. The fate of abstracts submitted to a cancer meeting: factors which influence presentation and subsequent publication. Ann Oncol 1992; 3: 187-191

[13] ECR 2010 Book of Abstracts. Insights Imaging. 2010; Suppl 1

[14] Arrive L, Dono P, Lewin M et al. Publication rate of original papers orally presented at the Journees Francaises de Radiologie 1996. J Radiol 2001; 82: $1719-1722$
[15] Yentis SM, Campbell FA, Lerman J. Publication of abstracts presented at anaesthesia meetings. Canadian Journal of Anaesthesia 1993; 40: $632-634$

[16] Krzyzanowska MK, Pintilie M, Tannock IF. Factors associated with failure to publish large randomized trials presented at an oncology meeting. The Journal of the American Medical Association 2003; 290: 495-501

[17] Egger M, Zellweger-Zahner T, Schneider M et al. Language bias in randomised controlled trials published in English and German. Lancet 1997; 350: $326-329$

[18] Weber EJ, Callaham ML, Wears RL et al. Unpublished research from a medical specialty meeting: why investigators fail to publish. The Journal of the American Medical Association 1998; 280: 257-259

[19] Sprague S, Bhandari M, Devereaux PJ et al. Barriers to full-text publication following presentation of abstracts at annual orthopaedic meetings. The Journal of Bone and Joint Surgery 2003; 85: 158-163 